\title{
Article
}

\section{A qualitative study of the label of personality disorder from the perspectives of people with lived experience and occupational experience}

Lamph, Gary, Jassat, Raeesa, Elliott, Alison and Mckeown, Michael Available at http://clok.uclan.ac.uk/39042/

Lamph, Gary ORCID: 0000-0002-4099-2812, Jassat, Raeesa, Elliott, Alison and Mckeown, Michael ORCID: 0000-0003-0235-1923 (2021) A qualitative study of the label of personality disorder from the perspectives of people with lived experience and occupational experience. Mental Health Review Journal . ISSN $1361-9322$

It is advisable to refer to the publisher's version if you intend to cite from the work.

For more information about UCLan's research in this area go to http://www.uclan.ac.uk/researchgroups/ and search for <name of research Group>.

For information about Research generally at UCLan please go to http://www.uclan.ac.uk/research/

All outputs in CLoK are protected by Intellectual Property Rights law, including Copyright law. Copyright, IPR and Moral Rights for the works on this site are retained by the individual authors and/or other copyright owners. Terms and conditions for use of this material are defined in the policies page. 


\title{
A qualitative study of the label of personality disorder from the perspectives of people with lived experience and occupational experience
}

\begin{abstract}
Purpose: The label 'Personality Disorder' continues to divide opinion. Challenges to the terminology of personality disorder led by people with lived experience and supported by critical practitioners and academics are tempered by acknowledgement of certain positive social consequences of obtaining a diagnosis. As such, it is opportune to engage service users and staff in a process of inquiry to better understand the complexities of views on the terminology of Personality Disorder.
\end{abstract}

Design / Methodology / Approach: This study set out to qualitatively explore the views of a range of people with lived, occupational and dual lived experience / occupational expertise, relating to the diagnostic label of Personality Disorder, via participatory and critical group debate. The World Café approach is an innovative methodology for participatory inquiry into subjective views suited to exploring contested subject matter.

Findings: This study identified contrasting opinions towards the label of Personality Disorder and provides insight into the concerns described for both keeping and losing the label. Although many felt the words 'personality' and 'disorder' are not in themselves helpful, certain positive views were also revealed. Perspectives towards the label were influenced by the way in which diagnosis was explained and understood by patients and practitioners, alongside the extent to which service provision and evidence-based interventions were offered.

Originality: This study brings together a wide range of views and experiences of mental health professionals, individuals lived experience and those who align to both lived and occupational expertise. A safe space was provided via the uniquely co-produced world café research event to bring together discussion and debates from mixed perspectives makes this a novel study. The focus being on perspectives towards contested language, labelling and social impact adds to scholarship in this field

Research / Practical / Social Implications: The findings have potential to contribute to ongoing critical debate regarding the value of the Personality Disorder construct in the provision of care and support. Specific emphasis upon the relational framing of care provision offers a means to ameliorate some of the negative impacts of terminology. Perspectives are influenced in the way the label understood hence attention is required to 
enhance these processes in clinical practice. There is much more work required to overcome stigmatisation, prejudice, and lack of knowledge and understanding. Further research identifying means for challenging stigma and the factors contributing to positive clinical interactions are required.

Key words: World Café Event, Personality Disorder, Stigma, Diagnosis, Labelling, CoProduction

\section{Introduction}

The label 'Personality Disorder' continues to divide opinion (Fairfax, 2011) and has become associated with negative connotations, stigma and uncertainty (Mind, 2018). This has led to a growing body of opinion seeking to challenge the terminology of personality disorder, which includes people with lived experience, campaigning groups, critical practitioners and academics. However, others suggest that renaming or removing the diagnosis could have a negative impact on aspects of care provision and research and make it more difficult for people to access evidence-based treatments. Arguably, losing the label completely could be deemed harmful, as without an agreed term to frame difficulties the direction and availability of treatment would prove challenging (Livesley \& Larstone, 2018). Despite some relevant research, much of the critical disposition to the label is informed by longstanding theoretical critique of the Personality Disorder construct and anecdotal reporting of dissatisfactions. There is a need to add to the empirical foundations for this important critical debate.

\section{Background}

There is much controversy around the diagnostic label 'Personality Disorder'. Some suggest that the Personality Disorder diagnosis has highlighted health and social inequalities (Moran et al., 2016; Fok et al., 2012) and is thus influential to policymakers and the commissioning of services. Diagnosis has advantages as a social concept by enabling access to state support, including housing, welfare benefits and social services, as well as leading to the provision of evidence-based treatments. Evidence-based treatments for Personality Disorder such as Dialectical Behaviour Therapy (DBT), Mentalisation-Based Therapy (MBT), and Structured Clinical Management (SCM) demonstrate encouraging efficacy (Chio-Kain et al., 2017). Receiving the diagnosis has also been described as key to enabling understanding and empowering patients to make informed decisions about the treatment options available to them (Bolton et al., 2014).

However, the availability and choice of interventions is widely acknowledged as being inconsistent across the UK (Mind, 2018). Inconsistent service provision has been in part attributed to a pervasive stigma and misunderstanding towards the label, undermining self- 
regard amongst individuals with the diagnosis (Sheehan, 2016). As a consequence, many people with lived experience have taken a critical view of the use of the diagnostic label (e.g. user-led activist collective Recovery in the Bin (see 2016 and Personality Disorder in the Bin); though it is also apparent that a heterogeneity of views exists within critical user/survivor groupings, encompassing outright rejection of the notion of diagnosis alongside a more nuanced appeal for alternative diagnostic approaches. It has also been argued that people in receipt of the diagnosis are often let down by complex social and system failures, driven in part by the label itself and thus requiring its revision (Mind, 2018).

Some argue these failures surround the nosology of personality disorder (Watts 2019), although many in the field fear that altering the diagnostic category and label itself merely addresses linguistic concerns as opposed to its associated complexities. Efforts to improve service response over the past decade have instead focused attention on national programmes (e.g. NIHME 2003a; 2003b) set up to challenge therapeutic nihilism. The provision of the Knowledge and Understanding Framework (KUF) Personality Disorder training (Baldwin et al., 2019) specifically sought to improve the skills and knowledge of the workforce. However, despite national programmes of education such as these, recent influential policy documents (e.g. Mind, 2018; Royal College of Psychiatrists, 2020) highlight ongoing problems with service provision and stigma. Some argue that after a decade of workforce education there has been limited benefits in addressing the controversy surrounding Personality Disorder which raises the broader question of how the label is currently perceived by both patients and staff.

Patient attitudes towards the diagnostic label have been explored over the years, with Lester et al. (2020) conducting a systematic review of patients' experiences of receiving a diagnosis. This review, however, focussed solely on service user perspectives. They conclude that the 'how' rather than the 'what' is fundamental to the experience of receiving a diagnosis of personality disorder with emphasis on how it is explained however also highlight the sensitivities, stigma and considerations for changing the label.

There is a lack of empirical research exploring the combined perspectives of those with lived experience and those with occupational experience through the process of discussion and debate. Perspectives of professionals towards the label have been particularly underresearched to date with a greater leaning towards patient perspectives. Given the extent to which workforce development has taken centre stage in efforts to reduce stigma, research into professionals' experiences is of considerable importance. Moreover, increased understanding of the extent to which patient and professional perspectives align may shed light upon the reason for the label's ongoing controversy. This research study provides novel 
insights to further compliment this research, given its additional inclusion of occupational expertise, thus providing a broader exploration of perspectives and experiences.

\section{Aim}

To explore the subjective and combined views of people with occupational experience and those with lived experience towards the diagnostic label of Personality Disorder. This will be achieved through discussion and debate. A subsidiary aim was to focus analysis upon participants' use of language relating to the diagnostic label.

\section{Method}

\section{Study Design}

The research took place at the $20^{\text {th }}$ Annual British and Irish Group for the Study of Personality Disorder Conference (BIGSPD) in Durham, England 2019. The core research team recruited to the study had a balanced composition of researchers with both lived experience and occupational experience. This ensured a unique and balanced model of coproduction amongst the research team was employed throughout development, implementation, analysis and dissemination phases.

A novel World Café event research methodology was adopted in order to provide a flexible and effective qualitative approach to capturing participants' views in a large group format. This approach was developed within organisational studies and is lauded for contributions to change practices concerned with accessing collective understandings of complex subject matter (Brown et al. 2010). A World Café data collection process moves participants around various facilitated workstations where they deliberate in small groups on defined issues or questions, acting to iteratively build responses, highlighting points of consensus or difference. This enables a richer gathering of collective intelligence pertaining to a particular discussion, the data from which can be captured in depth by both facilitators and participants themselves (Maskrey and Underhill, 2014). The approach is implicitly democratic and participatory and has been utilised successfully in various health related studies (Fouche \& Light 2011; MacFarlane et al. 2017, Stockigt \& Witt, 2013). The World Café event was guided by seven key methodological principles (Table 1) and provided an established framework upon which to structure the research.

Each workstation was co-facilitated by one person with relevant lived experience and one person with occupational experience in order to mitigate potential power imbalances between participants from respective groups. Co-facilitators were recruited via advertisement on a social media platform, with training and support provided by the core research team prior to the event. Training addressed both the methodology of a World Café approach and 
the necessity of capturing all participants' voices accurately whilst holding potential power differentials in mind.

The research involved two distinct phases. Phase 1 focussed upon the gathering of data using World Café event methodology, in which data was collected from conference delegates from both lived and occupational perspectives. Phase 2 focussed upon collecting the views of the World Café co-facilitators following the event via a harvesting meeting.

Ethical approval was granted by the University of Central Lancashire (Unique Reference Number - STEMH 977).

Table 1 - Key Principles when using the World Café methodology (Adapted from Maskrey and Underhill (2014)

1. Set the context - An exploration of critical discussion and debate relating to the label of personality disorder was outlined at the participant recruitment phase. A pre-event presentation set the scene, group rules and expectations of the event.

2. Create a hospitable space - Clear guidance was given to participants regarding the importance of equal opportunities to present views (both verbally and in writing). Tables were decorated with a range of welcoming decorations, including paper tablecloths for participants and co-facilitators to record written responses to the discussion themes. Pastoral support was also provided.

3. Explore the questions that matter - Topic areas and opening questions were developed by the core research team alongside in-depth prompts which were reviewed and shared with co-facilitators to guide discussion.

4. Encourage everyone's contribution - Co-facilitators were provided with pre-event training and a pre-event meeting to highlight the importance of all views being captured. 5. Connect via diverse perspectives - Moving around discussion tables ensured all participants were able to add to the developing debates, with each group building on the previous groups written data available on the tablecloths in front of them. The mixed-group selection of both lived and occupational experience on each table also added to this principle.

6. Listen for patterns and insights - Co-facilitators shared agreement on the emerging key themes and highlighted them throughout on the tablecloths, maintaining a balanced summary of findings. These were also fed back at the Phase 2 harvesting meeting.

7. Share collective discoveries - Co-facilitators engaged in a post-event harvesting meeting to debrief and capture the key themes to emerging from each discussion. The harvesting meeting was audio recorded, transcribed verbatim and considered within the 
wider reporting and analysis of data. Provisional headline findings were shared with the whole of conference the following day.

\section{Development of World Café Discussion Themes}

Core research team members developed the World Café discussion topics during an inperson meeting and generated three areas for discussion based upon themes perceived as relevant to the label of Personality Disorder. Specifically, the study aimed to capture participant views towards the following topic areas: i) the emotional aspect of the label, ii) the impact of the label, and iii) future directions for the label. Opening questions were also developed to aid co-facilitators in generating discussion. In order to mitigate core researcher biases, reflexive practice was adopted and feedback on the identified discussion topics were provided by co-facilitators.

\section{Study Sample}

\section{Phase 1}

A purposive sample was recruited from confirmed conference delegates who expressed an interest in participating. Those expressing interest were recruited on a first-come first-served basis, stratified to lived and occupational experience to ensure both perspectives were represented.

A pragmatic decision was made to cap the sample size at $n=48$ in order to ensure all participants had the chance to meaningfully contribute owing to the practicalities of hosting a world café event within the constraints of a national conference. In total 48 participants were recruited from 63 expressions of interest, with 44 participating in the event and 4 withdrawing beforehand.

Participants were assigned to groups of 8 across 6 workstations, with a ratio of $6: 2$ occupational experience to lived experience across the tables. In total, 32 participants aligned themselves to having occupational experience of working with people with a label of Personality Disorder, 4 participants aligned themselves to having lived experience of Personality Disorder, and 8 participants aligned themselves to both lived and occupational categories. For the purposes of sample distribution across workstations, those identified as belonging to the latter category were counted amongst those with lived experience.

\section{Phase 2}


Following the World Café event, co-facilitators were given the option of consenting to become participants in Phase 2 of the research. In total 12 co-facilitators were recruited to take part in the harvesting meeting (6 with occupational experience, 6 with lived experience).

Data Collection and Process

\section{Phase 1}

An introduction presentation was used to set the scene for the discussions and explain the process and methodology. Participants engaged in a series of discussions and debates surrounding the label of personality disorder. Six tables were split into two streams in order to ensure that all six groups visited each topic area twice, allowing for depth of discussion.

- Table 1A and 1B: Emotive aspects

- Table 2A and 2B: Impact of label

- Table 3A and 3B: Future directions

Each group spent 10 minutes on each table, visiting each table once. Throughout the event the core research team ensured the movement and flow of all groups. The event took 90 minutes in total.

Figure 1 - Flowchart Table Movements 


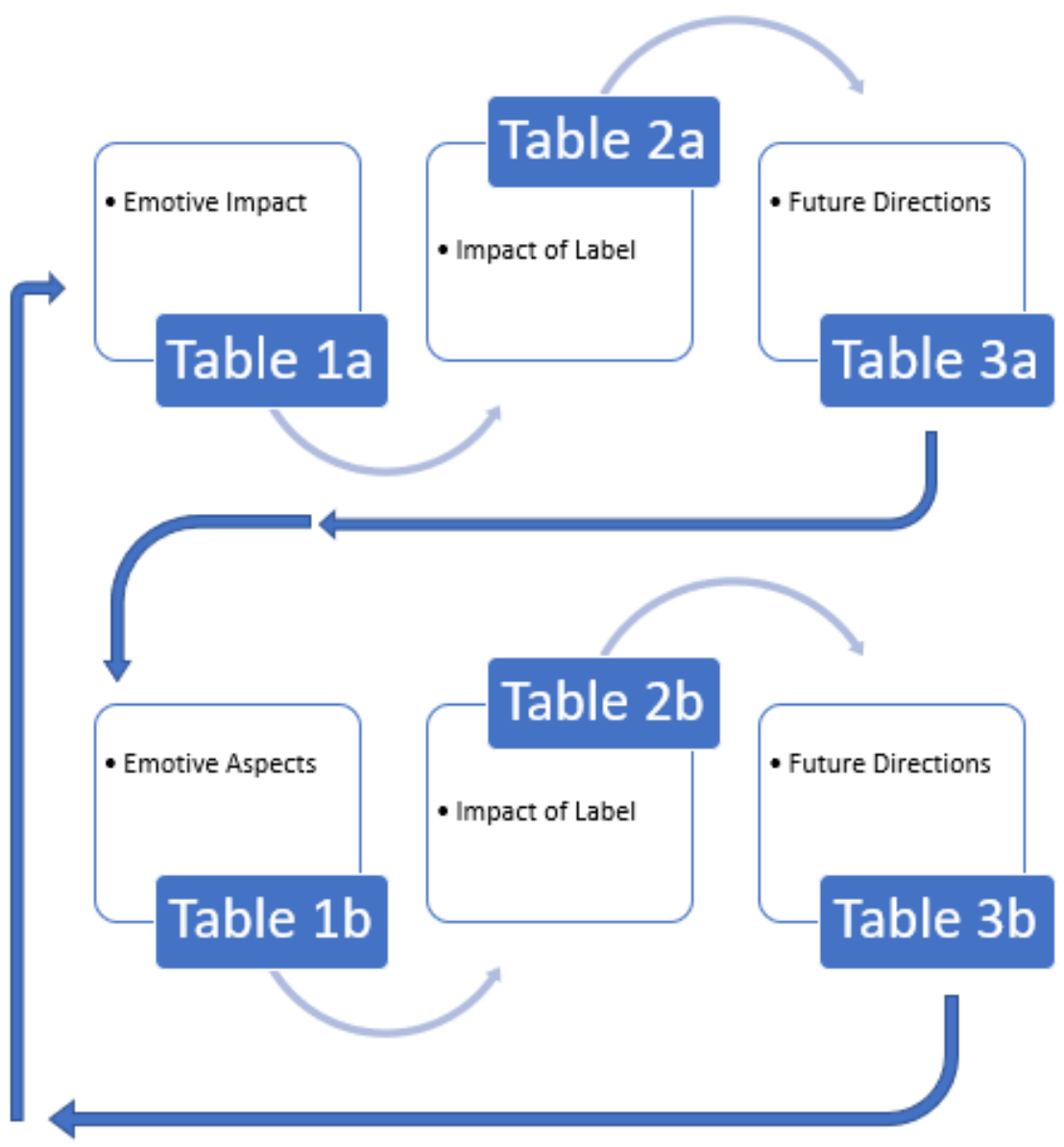

Two co-facilitators were responsible for each table and supported and captured data arising from the discussions. Co-facilitators opened up discussion using the developed opening question aligned to their topic area. During the discussion, one co-facilitator was responsible for supporting the flow of verbal debate, whilst the other captured the discussion on the tablecloth. Co-facilitators rotated roles at each round. Each group's participants were also given a coloured pen (distinguishable from those of co-facilitators and other groups) in order to personally capture written comments in response to the discussion.

Due to the potentially emotive discussion points three pastoral support members were recruited and made available throughout the event. An optional debrief session was also offered by the core research team to participants in order to raise any concerns with the event. Neither pastoral staff nor the debrief session were used by participants.

At the end of the World Café event, tablecloths were removed from conference and securely held.

\section{Phase 2}


Following the World Café event, co-facilitators added their own viewpoints and highlighted additional perspectives they felt to be unaccounted for by the data recording. This harvesting meeting took 60 minutes and was recorded on an encrypted audio recording device. Additional written notes were also held securely.

\section{Data Analysis}

A thematic analysis (Braun \& Clarke, 2006) was adopted to analyze the data, with each of the topic areas analysed independently of each other. The rationale for this being based on the three different topic areas being discussed. To enable this process, all written data were collated into an Excel spreadsheet. The harvesting meeting was transcribed verbatim. Data were securely held on a password-protected spreadsheet. All members of the core research team independently immersed themselves into the data before meeting to collectively undertake analysis. Although the focus of the respective tables provided some initial structure, analysis proceeded inductively, with coding of themes drawn directly from the raw data in a 'bottom up' approach. Reflexive dialogue amongst the research team was embedded throughout the analytic process, hence reducing the risk of reporting preconceived deductive themes and researcher bias. Thematic analysis took the form of a constructionist method that attempted to make sense of experiences, meanings and the realities of the views shared, and focused upon perspectives of language relating to the label (Braun \& Clarke, 2006). Table 2 provides an overview of the 6 phases of thematic analysis applied. This process of thematic analysis was initially performed by the core research team ( $x 4$ sets of initials to be added once anonymized review has taken place), followed by external independent analysis by 2 experienced researchers ( $x 2$ initials to be added) in order to establish consistency and consensus on the reported results and their alignment to the raw data. Following the analyses of the Phase 1 and Phase 2 data, these data were collectively considered and synthesized to present the results with reference to the workstation themes.

Table 2 - 6 Phases of Thematic Analysis; Phase and Application (Braun and Clarke, 2006)

\begin{tabular}{|l|l|}
\hline Phases & Application \\
\hline $\begin{array}{l}\text { Phase 1: Familiarisation } \\
\text { with the Data }\end{array}$ & $\begin{array}{l}\text { The core research team (Initials) were involved in all stages of } \\
\text { the data collection, whilst not directly responsible for data } \\
\text { collection in the world café they were present and observant of } \\
\text { the discussions taking place. They also hosted the harvesting } \\
\text { meeting and were all immersed into the raw data via its data }\end{array}$ \\
\hline
\end{tabular}




\begin{tabular}{|l|l|}
\hline & $\begin{array}{l}\text { management processes and provision of the recorded } \\
\text { harvesting meeting. }\end{array}$ \\
\hline $\begin{array}{l}\text { Phase 2: Generating } \\
\text { initial codes }\end{array}$ & $\begin{array}{l}\text { Initial coding of the raw data was achieved at a core research } \\
\text { meeting (Initials) in which all data was reviewed. Codes for } \\
\text { organising the themes were agreed for managing and } \\
\text { grouping the raw data in each of the topic areas }\end{array}$ \\
\hline $\begin{array}{l}\text { Phase 3: searching for } \\
\text { themes }\end{array}$ & $\begin{array}{l}\text { An initial thematic map for each of the topic areas was } \\
\text { developed. Each map was described, and discussion audio } \\
\text { recorded for future reflections and consensus between the } \\
\text { core research team that pertinent themes had been identified }\end{array}$ \\
\hline $\begin{array}{l}\text { Phase 4: Reviewing } \\
\text { Themes }\end{array}$ & $\begin{array}{l}\text { The thematic maps and recorded audios from phase 3 were } \\
\text { shared with external independent analysts (Initials) and 1 of } \\
\text { the core research teams members (Initials) alongside the raw } \\
\text { data which was reviewed and compared to ensure consistency } \\
\text { and consensus of our reporting across all 3 topic areas } \\
\text { covered. }\end{array}$ \\
\hline $\begin{array}{l}\text { Phase 5: Defining and } \\
\text { Naming the Themes }\end{array}$ & $\begin{array}{l}\text { Several reviews and iterations were achieved. The publication } \\
\text { process enabled the core and extended research team } \\
\text { analysists to agree upon meaningful and accurate reporting of } \\
\text { the results that are aligned to raw data. }\end{array}$ \\
\hline $\begin{array}{l}\text { Phase 6 Producing the } \\
\text { Report }\end{array}$ & $\begin{array}{l}\text { All authors contributed towards the articulation and description } \\
\text { of the analysed data reported, its interpretation and discussion } \\
\text { and findings reported. }\end{array}$ \\
\hline
\end{tabular}

\section{Results}

Themes generated are reported in each of the discussion topic areas, with the data set from each of the topic areas being independently analysed. Results and generated themes are described and outlined in table 3.

Table 3 - Table of Topic Areas and Generated Themes

\begin{tabular}{|l|l|l|}
\hline Topic Area & $\begin{array}{l}\text { Tables } \\
\text { (figure 1) }\end{array}$ & $\begin{array}{l}\text { Results } \\
\text { Themes reported }\end{array}$ \\
\hline Emotive Aspects & 1A \& 1B & $\begin{array}{l}\text { 1) Defectiveness } \\
\text { and Shame } \\
\text { 2) Retaining } \\
\text { Humanity }\end{array}$ \\
\hline Impact of Label & 2A \& 2B & $\begin{array}{l}\text { 1) Stigma and } \\
\text { Discrimination } \\
\text { 2) A 'Disordered' } \\
\text { Personality } \\
\text { 3) Treatment } \\
\text { Trajectory }\end{array}$ \\
\hline
\end{tabular}




\begin{tabular}{|l|l|l|}
\hline Future Directions & 3A \& 3B & $\begin{array}{l}\text { 1) Questioning the } \\
\text { Label } \\
\end{array}$ \\
& & $\begin{array}{l}\text { 2) Different } \\
\text { Approaches } \\
\text { 3) Attitude Change }\end{array}$ \\
\hline
\end{tabular}

\section{Emotive Aspects}

The discussion centring emotive aspects of the label 'personality disorder' was itself emotionally charged, with strong language frequently recorded within the data. Two themes were identified: 1) Defectiveness and Shame and 2) Retaining Humanity.

\section{Defectiveness and Shame}

Participants expressed a sense of personal defectiveness and shame as being an emotion strongly associated with the label of Personality Disorder. The label was repeatedly described as being "deeply shaming for an individual", and that identification with the label opened up a "vulnerability to shame". Such feelings of shame were typically experienced alongside related intense emotions, namely "anxiety" and "dismay", and led to reports that individuals feeling of "anger, hopelessness [and] worthlessness". Participants described the impact of shame not only upon on emotions but upon their willingness to seek treatment and support: "[Self] stigma stopped me accessing treatment for almost a decade."

Many participants attributed shame to a sense of "defectiveness" which was "demonising" and associated with a sense of blame for a person's own problems. One participant summarised this as follows:

"Trauma [is] hard to think about. Stigma. Shame and defective[ness]. It is invalidating. Society has let people down. We don't like to admit it. [The label] protects people around the person: 'all the fault is with them'...People already think 'it's my fault'. PD label re-enforces that."

Shame for the participants therefore highlighted related concepts such as personal responsibility for suffering and societal responses to the trauma typically associated with Personality Disorder.

\section{Retaining Humanity}

Participants described the notion of retaining an individual's humanity as implicit in the emotions generated when considering the label of 'personality disorder'. The extent to which participants felt those with the diagnosis remained "human first and foremost" was closely related to whether their emotional reaction to the label whether that be positive or negative. Where more positive responses were identified by participants reports of empathetic and humanised associations were reported:

"The term can make me smile [and] think of the community of creative, resilient, inspiring people l've met over many years." 
Indeed, creativity and resilience were frequently highlighted as positive traits of individuals diagnosed. The reporting of such attitudes coincided with the belief that the label is "not always a bad thing." A sense of relief was often felt as a direct consequence of diagnosis when seen as relating to a shared identity with others. Specifically, a valued "community grows from diagnosis."

However in contrast, other participants held strong negative views of the diagnosis when it was perceived as obscuring humanity or identity beyond that of being 'disordered': "I'm not just $P D$ - there is more to me". Some described an opinion that highlighted the ways in which the diagnosis appears to be given to those more disadvantaged within society: "only the disadvantaged get the labels, not MPs, presidents, CEOs etc". Concerns were shared over minority groups who receive the label who may already experience dehumanisation in the form of racism or gender non-conformity. This perspective involved participants' expression of more negative emotions relating to injustice: "shit childhood, shit label, shit stigma - what did I do to deserve that?". Loss of the individual to a diagnosis prompted further concern over wider societal failure and political neglect, suggesting that those diagnosed described as being treated like "second-class citizens" due to the label legitimising discrimination.

\section{Impact of Label}

The discussion that took place regarding the impact of the label 'personality disorder' considered how the label impacts on a variety of people and its broader systemic consequences. Three themes were identified: 1) Stigma and Discrimination, 2) A 'Disordered' Personality and 3) Treatment Trajectory.

\section{Stigma and Discrimination}

Participants felt that stigma and discrimination continues to be attached to the label of Personality Disorder.

Participants described such stigma as arising from misconceptions surrounding the difficulties people with this diagnosis often present with, with blame being attributed to the individual's "core self' or being "born bad". Where trauma was acknowledged as a factor in the receipt the diagnosis, stigma was described as being transferred to carers or family: "the label can imply negative things towards carers, e.g. 'you traumatised your child."' This was described as leading to furthering divisions of blame within families that may preclude therapeutic involvement.

A variety of examples of discrimination towards those with the label were described. This included exclusion from both mental health services and wider services such as local authorities, social housing providers and community groups. Discrimination within physical health settings was frequently cited: "the diagnosis masks other serious problems - someone with a stroke being offered psychiatric help before physical help." Such exclusion was felt to be compounded by the complaints of those labelled not being taken seriously: "When people have genuine complaints [they are] seen as playing to type". 
Participants with occupational experience described stigma towards the label as reaching across multiple levels, affecting not just the person with the diagnosis but referrals from clinicians within a dedicated personality disorder service:

"Staff can experience vicarious exclusion from services when trying to signpost service users because the label impacts on the perspectives of other service providers when it's included on referral forms e.g. 'we don't feel this was an appropriate referral.' Why not?! 'We don't like accepting referrals from your service.' Why not?"

In such instances, poor understanding of the label within the wider community was often cited as an explanation.

Whilst the existence of stigma and discrimination was widely acknowledged amongst participants, it is of note that experiences of exclusion were not described as being universal. For some, the label enabled access to services able to provide appropriate intervention or opportunities to work in co-production. In such circumstances, a sense of hope, belonging and relief were described, as well as enabling the signposting of available knowledge and skills that enabled people to not feel alone.

\section{A 'Disordered' Personality}

The very language used within the label Personality Disorder was felt to be impactful by participants. Participants made reference to the conception of 'personality' as allencompassing, with the consequence that to refer to one's personality as 'disordered' indicates one's "character is flawed". As one participant described: "[the label] implies there is something wrong with the very core of who I am". It was cited that one potential impact of this is that others may be less inclined to explore and understand the uniqueness of the affected person's difficulties, leaving unmet needs overlooked. Similarly, participants referred to the idea that 'personality' implies permanence, and that therefore people will "never be able to shake off the label'. Many participants also emphasised how the words themselves sound to those without a more detailed knowledge of the diagnostic category: "[It] sounds awful for the families and friends to hear it". Due to these impacts, some participants described the potential for iatrogenic harm.

It was highlighted, however, that 'personality disorder' specialist services exist. Therefore, the label can also facilitate access to a service better positioned to provide appropriate intervention.

\section{Treatment Trajectories}

The label 'personality disorder' was described by participants as impacting on treatment trajectory itself, and in particular upon the relational experiences encountered within services. This was seen as having potential to occur in either a positive or a negative direction.

Some participants highlighted the label as enabling access to specialised services, to "people who can help". Receiving certain types of group treatment, such as belonging to a Therapeutic Community, was considered positive in helping individuals see that "they are not the only one". The sense of belonging within a therapeutic context was seen as being "a relief'. The label was also perceived as enabling signposting and opening possibilities for accessing information resources. There was a particular emphasis among participants upon 
the importance of clinicians delivering the diagnosis appropriately. It was felt that where individuals were reassured of its treatability, this would "give hope" and led to feelings of empowerment. Some participants further described receiving the label as "stopping [people] from being described as mentally ill', a conceptual shift that was positively received.

Other participants described a more negative treatment trajectory as an impact of receiving the diagnosis. Some described the label being given with "no explanation" or "no reassurance that they can get better", and a perception that many staff did not possess an adequate understanding of the diagnosis. Numerous participants highlighted the need for more rigorous and transparent diagnostic procedures and assessments in addressing this. A related concern surrounded the label being withheld from the person to whom it refers due to stigma, with the consequence that its "difficulties are then invisible".

Whilst some participants felt that the label opens up treatment pathways, in others the opposite view was held that a diagnosis of 'personality disorder' remains a "diagnosis of exclusion". This was described as being attributed to a "lack of staff knowledge and skills", but also as a systemic "judgment". Indeed, participants described some services as refusing to accept referrals for patients with the diagnosis, leading to a sense of hopelessness.

The disparity between potential treatment trajectories and relational experiences was acknowledged by participants, recognising that "label impact is dependent upon place and time".

\section{Future Directions}

Three themes emerged from participants' discussion surrounding future directions for the label of personality disorder: 1) Questioning the Label, 2) Different Approaches, and 3) Attitude Change.

\section{Questioning the Label}

When considering future directions for the label 'personality disorder', participants reflected upon the rationale for changing the label itself. Views were expressed in favour of both changing the label and of keeping it unchanged.

Some of those suggesting a need for a change in label referred to the conceptual complexity of the word 'personality' and highlighted a need to move away from associating difficulties with personality altogether. A number of alternative labels were proposed, including "complex trauma", "emotional dysregulation syndrome", or operating on a "spectrum of personality". Some pointed to the shift in diagnostic terms within 'Learning Disability' as an example of change being possible. Others described a need to avoid labels altogether: "labels can end up reductive - and subsequently people are alienated". An alternative was presented in which formulation-based frameworks might ask "what happened to you" instead of labelling "what is wrong with you". Rationales for changing the diagnosis were varied, including that its historic negative connotations were difficult to move away from, and that 'personality disorder' is simply not very descriptive.

Participants who described a preference for retaining the existing label also articulated a range of views. Some suggested that "whatever you call it, it is still a label" and that any new 
term will simply adopt the controversy associated with the existing label. Some expressed concern that a shift from thinking about 'personality disorder' as 'complex trauma' could risk "putting people in subgroups of 'worthy' and 'not worthy' based on the subjective experience of trauma" leading to further stigma if one is deemed "not traumatised enough". Others stated that the changing the label itself would not be enough: "it's not a different label that's needed - it's a whole different way of looking at how we get messed up in our lives".

Political and economic considerations also featured in participants' descriptions in favour of retaining the label: "we won't get commissioned if we don't have some kind of label". In this sense, the label was perceived by some as being "a useful political term", and there was a fear that "speaking as if personality disorder doesn't exist undermines conversation with government/funders". Finally, some participants expressed a concern that targeted research could not occur without categories.

\section{Different Approaches}

Participants explored the models of practice and interventions that could be offered to people with the label 'personality disorder' in the future.

In the first instance, participants highlighted access to services as a salient issue. The current "postcode lottery" of service provision in the UK was described, as well as reemphasising themes surrounding exclusion from services. A variety of approaches were described as having potential to remedy this: "proper funding of current services"; "new generation of staff with a different outlook"; "training for staff"; and "clear frameworks to underpin practice/services". Participants also suggested a need to simplify interventions and a move away from psychiatric or psychological jargon in order to facilitate better access to services.

Participants described a wish for relational changes within and between services, highlighting that 'it's not solely the 'diagnosis'...it's been the experience of ill-equipped treatment over the previous years. Relationship matters more than diagnosis". In reflecting on this, participants described the importance of a trauma-informed approach over diagnostic approaches and the need for staff to receive more clinical supervision in order to develop their competencies. It was felt that a trauma-informed approach was required at a systemic level, with a need for systems to co-operate and develop more relational environments that provide a focus on the interactions between service and patient. Systems were described as requiring more compassionate leadership as well as the need to develop consistency amongst the workforce.

Several suggestions were also made regarding specific treatment approaches. Some described the importance of "strengths-based approaches", with less emphasis upon patients' problems. Some suggested clinicians adopting a more biopsychosocial perspective, whereas others suggested individualised treatment that adopts formulation-driven approaches. Numerous participants referred to the Power Threat Meaning Framework (PMTF) (Johnstone et al., 2018) as a way of holding in mind an individual's unique experiences, difficulties, and opportunities.

Attitude Change

Participants considered the importance of attitude change towards the label 'personality disorder' when imagining more positive future directions. Many participants reported servicelevel negative attitudes that were perceived as contributing to the ongoing stigma, 
discrimination and exclusion. It was suggested that further opportunities are required for workforce development, and that there was a need to "value frontline staff and help them access training". Training opportunities were described as being particularly helpful when enhanced with lived experience involvement. Co-production was also seen as needing to reach beyond sharing a "personal journey" and to also inform policy development.

Many participants articulated a sense that the controversy associated with 'personality disorder' requires greater acceptance as a public health problem. Emphasising earlier intervention and Adverse Childhood Experiences (ACEs) was suggested as helping ameliorate negative attitudes, "ensuring good mental health is on the education agenda from primary school level'. Relatedly, participants stated that political attention and service development should not focus merely on mental health services, but the entire public health system: "knowledge should be in the right places [such as] education, housing and police".

Negative public attitudes were also described by participants, who felt that there needed to be a shift in the broader societal perception of the label 'personality disorder'. The media was described as being potentially influential in this regard: "TV soaps can influence a change in attitudes, getting the message out". It was acknowledged that, to date, many Hollywood depictions of 'personality disorder' have been ill-informed and that a change in the way the diagnosis is depicted may also go some way to changing public opinion.

\section{Discussion}

This research sought to depict for the first time the combined views of both lived and occupational experience perspectives towards the label 'personality disorder', using a novel qualitative World Café event methodology.

The results demonstrate that the label 'personality disorder' yielded a range of strong emotional reactions among participants. Some of these were cited as being positive, such as affording opportunities to form a community with people sharing similar difficulties or promoting advocacy. At the other end of the spectrum, participants felt powerful negative emotions towards the diagnosis, articulated through harsh language and critical comments surrounding the wider sociocultural context believed to be implicated in the problems with the label. Specifically, defectiveness and shame and issues relating to the need to retain humanity and understanding which is often compromised through lack of understanding were felt to be driving forces of these more negative emotions.

The impact of the label was manifold. Of primary concern was the issue of stigma and discrimination. Participants felt that stigma and discrimination operate not only across services leading to disempowerment, but also to the generation of self-stigma among those with lived experience. Importantly, however, this was not everybody's experience, as numerous participants reported helpful access to treatment or opportunities for working in co-production. As with the experiences of emotions raised, this suggests a significant degree of mixed attitudes and experiences among participants of this research, which is likely to be 
further complicated by the varied lived or occupational expertise and individual experiences they had encountered.

Further impacts of the diagnosis were attributed to the nature of the words 'personality' and 'disorder' which were generally felt to be unhelpful and, in some cases, causes of iatrogenic harm. However, participants agreed that the issues regarding the diagnosis were more than a mere linguistic concern, and thus perception of the label strongly correlated with relational experiences encountered surrounding the diagnosis. For those who experienced largely supportive attitudes (both as professionals working in such a clinical environment, and as patients receiving the diagnosis), the problematic language of the label when it appeared to be less damaging was still not overtly endorsed. Recent revisions to the diagnostic manuals have retained the terminology (World Health Organisation, 2019), Therefore it is likely that the label 'personality disorder' will remain for at least several more years.

The mixed views depicted among participants continued within discussion exploring future directions for the label, with many arguing for its retention and equally as many arguing for it to be changed. Interestingly, those arguing in favour of retaining the label were sympathetic towards its controversies but were concerned that a new label would similarly garner stigma and that ongoing debate around the label itself may obscure research into the more pressing clinical issues. Attitudes were more widely shared regarding treatment models and interventions: there was an agreement that the postcode lottery of treatment requires addressing, and that systemic problems in service delivery and public health require change at various levels (e.g. leadership and training). There was also a strong sense that it is stigma and misunderstanding which present a barrier going forward.

Participants' attitudes towards the label were predominantly influenced by their relational experiences as opposed to being solely based on the language used, which suggests that it is the experience of understanding, support, and inclusion which requires more attention. Where participants had containing relational experiences and found a sense of community or inclusion in services, the problematic language was considerably less damaging.

By bringing together lived and occupational expertise, this study offers an original addition to the literature in this field. Interestingly, the occupational experts highlight some implications and practicalities such as access to effective evidence-based treatments such as DBT, MBT, SCM (Chio-Kain et al., 2017), the variability of service provision (Dale et al., 2017) and implications for research funding, whereas lived experience perspectives were less focussed on these implications for practice. The inclusion therefore of mixed perspectives in studies where the subject matter is contested should be promoted. As our results indicate the need for caution and not to presume any one constituency holds a monopoly of salient viewpoint. 
This is especially important if we are to concern ourselves with democratic, coproduced solutions to identified problems and controversies. This research demonstrates that bringing together a broad range of occupational and lived experience perspectives can be achieved even in a highly sensitive context.

Whilst many questions remain and this research reinforces the complex landscape of attitudes surrounding the label of Personality Disorder, this study provides a unique insight into a broad range of experiences and in particular highlights some of the implications radical change may have on practice, including the loss of progress already made in this field, whilst acknowledging that the diagnosis remains fraught with challenges. There is a clear need to acknowledge the label is contentious and continues to cause distress for many whilst highlighting areas for improvement of experience. This research has begun to influence and provide a contribution to the funders the British and Irish Group for the Study of Personality Disorder (BIGSPD) and impacted upon the development of the organisational values, with attention to the challenges with the label represented within this research. Demands to change the label itself persist and require further exploration and consideration, however the implications for such change also needs to be carefully considered as do the various insights from the perspectives highlighted within this paper. There is a need to ensure that any progress made in this field of practice is not lost, whilst acknowledging the detrimental impact of certain diagnostic language and practices and ensuring progressive demands for change do not create a further negative impact on service provision and understanding for people who receive this diagnosis or have associated difficulties.

The biggest risk faced in losing the label is the loss of a framework that acts as an anchor point that enables services to organise themselves and their responsiveness to meeting the needs of the client group. Caution should be taken to avoid losing the progress already made in this field of practice, whilst holding in mind the need to be equally attentive to the challenges and sensitivities that continue to exist. It should be noted that change is afoot, with lots of reflections taking place, including the NIHR Policy Research Unit, who reframed the label as 'Complex Emotional Needs' (Sheridan Rains et al., 2021) and Royal College of Psychiatrist position statement (2020), which make the subtle movement away from the diagnosis label. Further examples of this are demonstrated in the Offender Personality Disorder pathway who are now referring to those diagnosable' and within their recent amendment to practitioner guidance referring to 'Personality Difficulties' instead of Personality Disorder (Craissati et al., 2020). Additionally, the consensus statement (Mind, 2018) also called for a move away from the diagnostic label. However, careful consideration and planning for any radical changes is essential, so to not lose progress or risk further regression in our responses to this client group. Any change needs to be done safely and 
through careful evolution hence reducing the risk of further isolating or excluding people with this diagnosis. This can be best achieved by recognising the benefits of a diagnosis alongside drawbacks to it.

\section{Limitations}

This research captures discussions relating to the label of Personality Disorder from both lived and occupational perspectives. One limitation, however, is the disproportionate number (6:2 ratio) of occupational participants compared to participants with lived experience. This increased the risk of power differentials amongst participants. In an attempt to mitigate for this our research team and co-facilitators were equally represented with occupational and lived experience ensuring all voices were heard and a hospitable space provided as per world café methodology was provided. A future study may be useful to distinguish the views of the occupational workforce and those with lived experience in greater depth, as well as collecting broader demographics in order to more clearly establish the kinds of voices being captured by the research.

The generalisability of our findings also present limitations, as participants were self-selected from registered conference delegates and had chosen to attend a conference that features the label 'Personality Disorder' within its title. Additionally, we recognise that participants in attendance may have influenced the range of strong opinions expressed as people with strong views were likely to be in attendance.

Some caution may also be taken on the generalisability of the findings to the wider population. Conference attendees are typically involved in personality disorder research or service provision, including at senior levels and many of those with lived experience also identified with a dual occupational expertise.

\section{Conclusion}

Our innovative approach to this research via its methodology and it being fully co-produced, co-delivered and inclusive of mixed perspectives by including a wide range of participants from both lived and occupational expert viewpoints, provides new insights and contributions to compliment this highly topical area of ongoing debate. Our approach and methods provide an authoritative and expert description of the key themes relevant to the debate. Attitudes towards the use of the diagnostic term 'Personality Disorder' remain mixed and strongly based on individual experience. Stigma, discrimination and exclusion was strongly reported despite national policies and initiatives to address this. There is therefore a vital need to continue to raise awareness of stigma and identify means of challenging this, as well as to identify which other factors mediate a positive diagnostic experience. 
Some of our results provide confirmations of other study findings highlighted in this area, however despite knowing of the challenges with this diagnostic label for many years, there is still an ongoing struggle to move forward or reach consensus, hence the concerns whilst voiced and building momentum remain largely unaddressed. The findings from this study will further put under the spotlight the need for meaningful reflections to be made. There is still much to learn relating to this debate and many challenges to overcome to understand, respond to, and erode the ongoing stigma and discrimination surrounding the label which include:

- Recognition that this label does not define the person

- People who receive this diagnosis are unique and heterogeneous

- Receiving the diagnosis, the way in which it is received, how it is delivered and how it is explained requires compassionate and comprehensive consideration with messages of hope and optimism embedded

- The ongoing provision of training to improve knowledge, awareness, insight is an ongoing challenge that needs to be continued

- Co-production practices involving people who have experienced life with this diagnosis should be fundamental to service provision, education and future research

- Service provision, choice and equitable accessible evidence-based service provision across the country is necessary

- Whole systems approaches are required to attend to stigma, discrimination and exclusion

- More research is required to understand and explore the implications of changing the label to ensure any progress is not lost that has already been made.

\section{References}

Baldwin, V., Blazdell, J., Gordon, N, S., Gordon, F. (2019) KUF Scoping Review. A review of the National Personality Disorder Knowledge and Understanding Framework. Ministry of Justice.

Bolton, W., Lovell, K., Morgan, L., Wood, H (2014) Meeting the challenge, making a difference: Working effectively to support people with personality disorder in the community. Project Report. Department of Health, London.

Braun, V. \& Clarke, V. (2006) Using thematic analysis in psychology. Qualitative Research in Psychology. 3 (2). pp. 77-101. ISSN. http://dx.doi.org/10.1191/1478088706qp063oa

Brown, J., Isaacs, D. \& The World Café Community. (2010) The world café: Shaping our futures through conversations that matter. San Fransisco, CA: Berret-Koehler Publishers. 
Choi-Kain, L, W., Finch, E, F., Masland, S, R., Jenkins, J, A. \& Unruh, B, T (2017) What works in the treatment of borderline personality disorder. Curr Behav Neurosci. Rep (2017)

4: 21. https://doi.org/10.1007/s40473-017-0103-z

Craissati, J., Joseph, N. \& Skett, S (2020) Working with people in the Criminal Justice System showing Personality Difficulties. (3rd Ed.) Department of Health / Ministry of Justice.

Dale O, Sethi F, Stanton C, Evans S, Barnicot K, Sedgwick R, Goldsack S, Doran M, Shoolbred L, Samele C, Urquia N, Haigh R, and Moran P. (2017) Personality disorder services in England: findings from a national survey. DOI: 10.1192/pb.bp.116.055251

Fairfax, H. (2011). Re-conceiving personality disorders: Adaptations on a dimension? Counselling Psychology Quarterly. 24, 313-322.

Fok ML-Y, Hayes RD, Chang C-K, Stewart R, Callard FJ \& Moran P (2012) Life expectancy at birth and all-cause mortality among people with personality disorder. Journal of Psychosomatic Research. 73(2):104-7.

Fouché, C. and Light, G., 2011. An Invitation to Dialogue: 'The World Café' In Social Work Research. Qualitative Social Work. 10(1), 28-48.

Johnstone, L. \& Boyle, M. with Cromby, J., Dillon, J., Harper, D., Kinderman, P., Longden, E., Pilgrim, D. \& Read, J. (2018). The Power Threat Meaning Framework: Towards the identification of patterns in emotional distress, unusual experiences and troubled or troubling behaviour, as an alternative to functional psychiatric diagnosis. Leicester: British Psychological Society. Power threat meaning framework. www.bps.org.uk/PTM-Main

Lester, R., Prescott, L., McCormack, M., \& Sampson, M (2020) Service users' experiences of receiving a diagnosis of borderline personality disorder: A systematic review. Personality and Mental Health. 14, 263-283. DIO10.1002/pmh.1478

Livesley, J, W \& Larstone, R. (2018) Handbook of Personality Disorders, Second Edition: Theory, Research, and Treatment. London; The Guilford Press.

MacFarlane, A., Galvin, R., O'Sullivan, M., Mclnerney, C., Meagher, E., Burke, D. and LeMaster, J.W. (2017). Participatory methods for research prioritization in primary care: an analysis of the World Café approach in Ireland and the USA. Family Practice, 34(3), 278284.

Maskrey, N. and Underhill, J. (2014) The European Statements of Hospital Pharmacy: Achieving consensus using Delphi and World Café Methodologies. European Journal of Hospital Pharmacy. 21, 264-266.

Mind (2018) Shining Lights in Dark Corners of People's Lives; The Consensus Statement for People with Complex Mental Health Difficulties who are diagnosed with a Personality Disorder. https://www.mind.org.uk/ media/21163353/consensus-statement-final.pdf.

Moran P, Romaniuk H, Coffey C, Chanen A, Degenhardt L, Borschmann R et al (2016) The influence of personality disorder on the future mental health and social adjustment of young adults: A population-based, longitudinal cohort study. The Lancet Psychiatry. 3(7):636-45. 
National Institute for Mental Health in England (2003a) Personality Disorder: No longer a diagnosis of exclusion, policy implementation guidance for the development of services for people with personality disorder. NIMHE: London.

National Institute for Mental Health in England (2003b) Breaking the Cycle of Rejection: The Personality Disorder Capabilities Framework. NIHME, London.

Recovery in the Bin (2016). A simple guide on how to avoid receiving a diagnosis of 'personality disorder'. Clinical Psychology Forum. 279, 13-16.

Royal College of Psychiatrists (2020) PS01/20: Services for people diagnosed with personality disorder. https://www.rcpsych.ac.uk/docs/default-source/improving-care/bettermh-policy/position-statements/ps01 20.pdf?sfvrsn=85af7fbc 2

Sheehan, L., Nieweglowski, K., Corrigan, P. (2016). The stigma of personality disorders. Current Psychiatry Reports. 18:1.

Sheridan Rains, L., Echave, A., Rees, J., Scott, H, R., Taylor, B, L., Broeckelman, E., Steare, T., Barnett, P., Cooper, C., Jeynes, T., Russel, J., Oram, S., Rowe, S. \& Johnston, S (2021) Service user experiences of community services for complex emotional needs: A qualitative thematic synthesis. PLoS one. 16 (4) 1-30.

https://doi.org/10.1371/journal.pone.0248316

Stockigt, M.T and Witt, C.M. (2013) CAM Use and Suggestions for Medical Care of Senior Citizens: A Qualitative Study Using the World Café Method. Evidence-Based Complimentary and Alternative Medicine

Watts, J (2019) Problems with the ICD-11 classification of personality disorder. The Lancet. 6, 461-463.

World Health Organisation. (2019) International Statistical Classification of Diseases and Related Health Problems. (11th Revision) http://www.who.int/classifications/icd/en/

Yang, M., Coid, J and Tyrer, P (2010) Personality pathology recorded by severity: national survey. British Journal of Psychiatry. 197, 193-9. 